\title{
O. Leplâtre, Fénelon ou l'inquiétude du politique
}

\section{Barbara Piqué}

\section{(Q) OpenEdition}

\section{Journals}

\section{Edizione digitale}

URL: http://journals.openedition.org/studifrancesi/9936

DOI: 10.4000/studifrancesi.9936

ISSN: 2421-5856

\section{Editore}

Rosenberg \& Sellier

\section{Edizione cartacea}

Data di pubblicazione: 1 août 2017

Paginazione: 355

ISSN: 0039-2944

\section{Notizia bibliografica digitale}

Barbara Piqué, «O. Leplâtre, Fénelon ou l'inquiétude du politique», Studi Francesi [Online], 182 (LXI | II) |

2017, online dal 01 août 2017, consultato il 08 janvier 2021. URL: http://journals.openedition.org/ studifrancesi/9936 ; DOI: https://doi.org/10.4000/studifrancesi.9936

\section{Questo documento è stato generato automaticamente il 8 janvier 2021.}

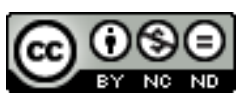

Studi Francesi è distribuita con Licenza Creative Commons Attribuzione - Non commerciale - Non opere derivate 4.0 Internazionale. 


\title{
O. Leplâtre, Fénelon ou l'inquiétude du politique
}

\author{
Barbara Piqué
}

\section{NOTIZIA}

OLIVIER LePLÂTRE, Fénelon ou l'inquiétude du politique, Paris, Hermann, 2015, 487 pp.

1 Il volume si iscrive nel rinnovato interesse che l'opera di Fénelon - gli scritti pedagogici come quelli spirituali - ha conosciuto nell'ultimo ventennio. Come l'indica il titolo, questo lavoro si concentra sulla riflessione politica dell'arcivescovo di Cambrai, già oggetto degli interessanti saggi raccolti negli atti del convegno di Strasburgo del 1999 (Fénelon. Mystique et politique, a cura di F.-X. Cuche e J. Le Brun, Paris, Champion, 2004). Ma la problematica che Olivier Leplâtre mette a fuoco non manca di originalità. Si tratta del complesso rapporto tra finzione narrativa e politica. Per quale motivo, si chiede Leplâtre, Fénelon, pur così attento alla cosa pubblica, non ha mai composto un'opera di teoria politica? Nelle tre dense parti che compongono il volume Leplâtre interroga questa omissione ed elabora una interpretazione critica non priva di suggestione.

2 La prima parte («L'impensable pensée politique») analizza le premesse del pensiero politico di Fénelon, preso tra un pessimismo antropologico che vede nel mondo «un Enfer déjà commencé», la necessità di un'arte del buon governo che di quest'inferno tenga conto, la figura del principe la cui natura umana ne fa una vittima delle passioni, e la coscienza che le passioni sono la fonte stessa dell'energia che sostanzia la politica. L' «inquiétude du politique» sta nella drammaticità di questa impasse.

3 Nella seconda parte («Épreuves de la fiction»), Leplâtre ripercorre i testi narrativi di Fénelon - opuscoli pedagogici, favole, Dialogues des morts e Télémaque - ravvisando nella creazione letteraria la forma più consona all'espressione del pensiero politico. Perché Fénelon preferì, a una riflessione teorica, la via della creazione letteraria? È sufficiente, per spiegarne le ragioni, addurre gli intenti pedagogici dell'autore - il suo ruolo di 
precettore del duca di Borgogna, per il quale scrisse queste opere - o una personale reinvenzione, nel solco della tradizione rinascimentale dei miroirs des Princes, di una paideia principesca? Motivi più profondi - e più complessi - emergono dall'interpretazione che delle opere narrative di Fénelon dà lo studioso. La finzione, osserva Leplâtre, "porte en elle-même une interrogation politique». Fénelon la piega infatti al progetto di mettere a nudo e sotto accusa il peso che assume l'immaginazione nella sfera del politico: la finzione narrativa si trova allora al servizio di una contestazione della finzione politica e, soprattutto, della «fictionalisation» del sociale. Conviene, insomma, guardare alla politica secondo Fénelon nella prospettiva stessa che la politica adotta per sostenersi e sostentarsi: quella, appunto, che permette di distinguere nell'«anamorphose des fictions vraies» le rappresentazioni delle «métamorphoses imaginaires» del politico. Le pagine dedicate a interpretare in questo senso le finzioni féneloniane sono di estremo interesse e sollecitano l'adesione del lettore grazie anche alle seduzioni di una riflessione critica «en abyme», o «au second degré».

4 «Le gouvernement des images», ultima parte del volume, vaglia il ruolo delle immagini in questi testi narrativi: un ruolo che, per il giovane duca di Borgogna, si proponeva come un risveglio all'arte, figura del divino pur nell'essenza transitoria della sua sostanza fittizia.

Olivier Leplâtre ha l'indubbio merito di dare una forma stilistica di grande raffinatezza alla sue analisi: fascino di una scrittura che non sempre, tuttavia, rende agevole la lettura e la comprensione sintetica del discorso critico. 